\title{
The Effect of Phosphoethanolamine Intake on Mortality and Macrophage Activity in Mice with Solid Ehrlich Tumors
}

\author{
Maria Sueli Parreira de Arruda ${ }^{1 *}$, Mara Adriana Correa ${ }^{1}$, James Venturini $^{1}$, Maira \\ Camila Félix ${ }^{1}$, Ana Maria Bormio De Rosis ${ }^{1}$, Mário Sérgio Galhiane ${ }^{2}$, Gilberto Orivaldo \\ Chierice $^{3}$ and Maria Renata Sales Nogueira Costa ${ }^{4}$ \\ ${ }^{I}$ Departamento de Ciências Biológicas; Faculdade de Ciências; Universidade Estadual Paulista; Av. Eng. Luiz \\ Edmundo Coube, 14-01; 17033-360; Bauru - SP - Brasil. ${ }^{2}$ Departamento de Química; Faculdade de Ciências; \\ Universidade Estadual Paulista; Bauru - SP - Brasil. ${ }^{3}$ Departamento de Química e Física Molecular; Universidade \\ de São Paulo; Av. Trabalhador São Carlense, 400; 13566-590; São Carlos - SP - Brasil. ${ }^{4}$ Insituto Lauro de Sousa \\ Lima; Rod. Com. João Ribeiro de Barros; Km 225/226; 17034-971; Bauru - SP - Brasil
}

\begin{abstract}
The aim of the present study was to examine the effect of a diet rich in synthetic PEtn on the metabolism macrophages of tumor-bearing mice. The results demonstrated that PEtn increased the animals' survival time. In addition, the treated animals released smaller amounts of hydrogen peroxide $\left(\mathrm{H}_{2} \mathrm{O}_{2}\right)$ and nitric oxide (NO) than the non-treated animals, particularly after day 14. From the results it could be concluded that $\mathrm{H}_{2} \mathrm{O}_{2}$ and $\mathrm{NO}$ were important in the modulation of neoplastic growth, and pointed to a promising role of PEtn in the control of human neoplasms.
\end{abstract}

Key words: Phosphoethanolamine, Ehrlich tumor, nitric oxide, hydrogen peroxide, lipids

\section{INTRODUCTION}

The genesis and progression of neoplasms of the breast, colon and prostate are influenced by multiple factors, one of which may be lipid ingestion and the resulting changes in the immune response (Erickson and Hubbard, 1996). Despite multiple studies in this area, the mechanisms involved in the process of tumor formation are not clear. The monoester phosphoethanolamine (PEtn) has been a target for many studies aiming to understand the tumorigenesis and the relationship between the phospholipids and tumor progression. Some authors believe that phospholipids lead to a decrease in tumor growth (Morvan et al., 2002 and
Aiken and Gillies, 1996), while other authors have asserted that an elevated level of these monoesters is related to the increased tumor growth (Campbell et al., 1990). The literature also shows that the diets with high lipid contents (especially polyunsaturated fatty acids, or PUFAs) may result in increased synthesis of surface membrane molecules (Sherrington et al., 1995), reduced lymphocyte proliferation, cytokine synthesis, and natural killer (NK) cell activation (Yaqoob et al., 1994). Thus, the depressed immune response that results from the increased lipid availability in the body may modulate neoplastic development.

The solid Ehrlich tumor is a spontaneous murine mammary tumor that does not resolve spontaneously. It has previously been employed to

*Author for correspondence: sueli@fc.unesp.br 
study the effects of herbal medicines and drugs on macrophage activity (Matsuzaki et al., 2003; Sakai et al., 2006). The choice to use the peritoneal macrophages was based on previous studies employing subcutaneous transplantation of AK-5 tumor cells (Mitra et al., 2004; Bhaumik et al., 1988, 2001). Those studies showed that the transplantation of AK-5 tumor cells into the subcutaneous tissue led to hyperactivation of the peritoneal macrophages. Later, there was depletion of the activated macrophages from the peritoneal cavity associated with the onset of AK-5 tumor regression. Direct labeling of hyperactivated macrophages in the peritoneum by the tracking dye PKH26 showed their migration to the tumor site. These findings provided functional evidence that peritoneal macrophages played a role in tumor progression and were thus critical cells to study the therapeutic approaches.

\section{MATERIAL AND METHODS}

\section{Mice}

Forty male Swiss two-month-old mice were purchased from the Animal House of the Central Laboratory of UNESP - Univ Estadual Paulista, Brazil. The mice were divided into two groups. The control (non-treated) group $(\mathrm{n}=20)$ was fed a normal commercial diet (Labina Purina ${ }^{\circledR}$, Paulinia, SP, Brazil), and the experimental (PEtn-treated) group $(n=20)$ was fed a commercial diet (Labina Purina ${ }^{\circledR}$ ) containing PEtn. The experimental protocol was designed in accordance with the ethical rules for animal research of the Brazilian College for Animal Experimentation.

\section{PEtn administration}

PEtn was purchased from the Chemistry Institute of São Carlos (USP - Universidade de São Paulo, Brazil) and added to a concentration of $800 \mathrm{mg} / \mathrm{kg}$ of animal food. Treatment began one week prior to tumor inoculation.

\section{Tumor model and histopathology}

The Ehrlich carcinoma strain used was purchased from the Department of Pathology of Botucatu Medical School, UNESP. Ehrlich ascites tumor cell (EATC) extraction followed a previously described technique (Silva et al., 2002). EATCs were inoculated subcutaneously $\left(10^{7}\right.$ cells/mouse $)$ to generate the solid tumors in both the control and experimental groups. Five animals from each group were killed by $\mathrm{CO}_{2}$ asphyxiation at days 7 , 14, 21, and 28 after tumor cell inoculation. Tumor samples were dissected from the skin and subcutaneous fat from the dorsum of each animal. The resulting specimens were fixed in buffered formalin for $48 \mathrm{~h}$ prior to preparation for the paraffin embedding. Tissue sections were stained with hematoxylin-eosin and evaluated under light optical microscopy.

\section{Preparation and stimulation of peritoneal macrophages}

Abdominal cavity washing to extract the peritoneal macrophages was carried out with $10 \mathrm{ml}$ of sterile ice-cold phosphate-buffered solution (PBS). The peritoneal lavage suspension was then centrifuged, and the cells were resuspended in RPMI 1640 medium (Nutricell, Campinas, SP, Brazil), supplemented with $10 \%$ heat-inactivated fetal calf serum (Gibco BRL, Grand Island, NY, USA). The cell number was adjusted to $2 \times 10^{6}$ cell//ml. Macrophage activation was demonstrated using the spreading test (Rabinovitch et al., 1977), and $\mathrm{H}_{2} \mathrm{O}_{2} / \mathrm{NO}$ production was also measured.

Peritoneal macrophages extracted for the spreading test were incubated in 199 culture medium (Sigma, St Louis, MO, USA) at $37^{\circ} \mathrm{C}$ for $60 \mathrm{~min}$. Glass-attached macrophages were fixed in $2.5 \%$ glutaraldehyde (Vetec, Duque de Caxias, RJ, Brazil), stained with hematoxylin-eosin, and then analyzed under light microscopy. The spreading test was based on the ability of macrophages, when activated, to adhere to glass and to spread; the percent of spreading macrophages was determined from 100 cells.

The production of $\mathrm{H}_{2} \mathrm{O}_{2}$ was evaluated in $10^{6}$ cells $/ \mathrm{ml}$ of peritoneal macrophages in supplemented phenol red solution, and cell absorbance was determined by enzyme-linked immunosorbent assay (ELISA) (Russo et al., 1989). NO concentration was measured with a nitrite production method in the culture supernatant (Ding et al., 1988). Briefly, macrophages $\left(10^{6}\right.$ cells $\left./ \mathrm{ml}\right)$ were incubated with RPMI 1640 culture medium in a 5\% $\mathrm{CO}_{2}$ atmosphere at $37^{\circ} \mathrm{C}$ for $48 \mathrm{~h}$. Subsequently, supernatant was added to Griess reagent supplemented with $1 \%$ sulfanilamide (Synth, Diadema, SP, Brazil), 0.1\% naphthylene diamine dihydrochloride (Sigma, St Louis, MO, USA) and $2.5 \% \mathrm{H}_{3} \mathrm{PO}_{4}$ at room temperature for $10 \mathrm{~min}$. Absorbance of nitrite was quantified by ELISA (ELx 800, Bio-tek Instruments Inc, USA). 


\section{Statistical analysis}

All the statistical tests were conducted using GraphPad InStat version 3.0 for Windows (GraphPad Software, San Diego, California, USA), and $p<0.05$ was considered statistically significant. When two averages were obtained, Student's $t$ test was used for their comparison. When more than two averages were obtained, ANOVA and the Tukey-Kramer post-test were used for comparison (Norman and Streiner, 1994).

\section{RESULTS}

\section{Tumor progression}

Animals in the non-treated group survived until 21 days after Ehrlich carcinoma inoculation, but did not survive past 28 days. The animals treated with the PEtn lived to the end of the experimentation period (28 days).

\section{Histopathology}

Altogether, microscopic analysis revealed only slight changes between the control and experimental groups. The tumor architecture in the treated and non-treated groups on day seven showed similar characteristics (Fig. 1A and Fig. 1B). The specimens showed central necrosis and stromal microabscesses, with atypical proliferative cells intermingled with mononuclear inflammatory infiltrates and early granulation tissue beneath. At day 14, histopathology of the PEtn-treated (Fig.
1C) specimens demonstrated a multilobulated tumor-growth pattern, with plasmolymphocytic inflammatory cells and partial delimitation by granulation tissue. The the neoplastic invasion was discreetly diminished, with an organization of the peripheric granulation tissue, suggestive of a fibrous capsule. At day 14, in the treated group, the observed pattern of cohesion of the tumor cells increased, whereas the non-treated group (Fig. 1E) showed blood vessel destruction by the tumor cells and less cohesion of neoplastic cells (Fig. 1F). At 21 days (Fig. $1 \mathrm{G}$ and Fig. $1 \mathrm{H}$ ), the non-treated animals demonstrated extensive necrosis of both the stroma and neoplasic cells as well as ulceration of the epidermis. There was extensive tumor invasion and disruption of the granulation tissue. These aspects were similar in the PEtn-treated animals. No non-treated mice survived to day 28 .

\section{Effects of PEtn on macrophage activity}

Tumor-bearing mice from both the non-treated and PEtn-treated groups demonstrated significant decreases in the macrophage-spreading capacity (Fig. 2A). However, only the macrophages from the PEtn-treated group demonstrated a significant decrease in $\mathrm{H}_{2} \mathrm{O}_{2}$ release at both 14 and 21 days (Fig. 2B). At day 14, both the groups showed reduced levels of $\mathrm{NO}$, followed by an increase at day 21 (Fig. 2C). At day 28, NO levels rose significantly in the PEtn-treated mice, but no control mice survived for the comparison.

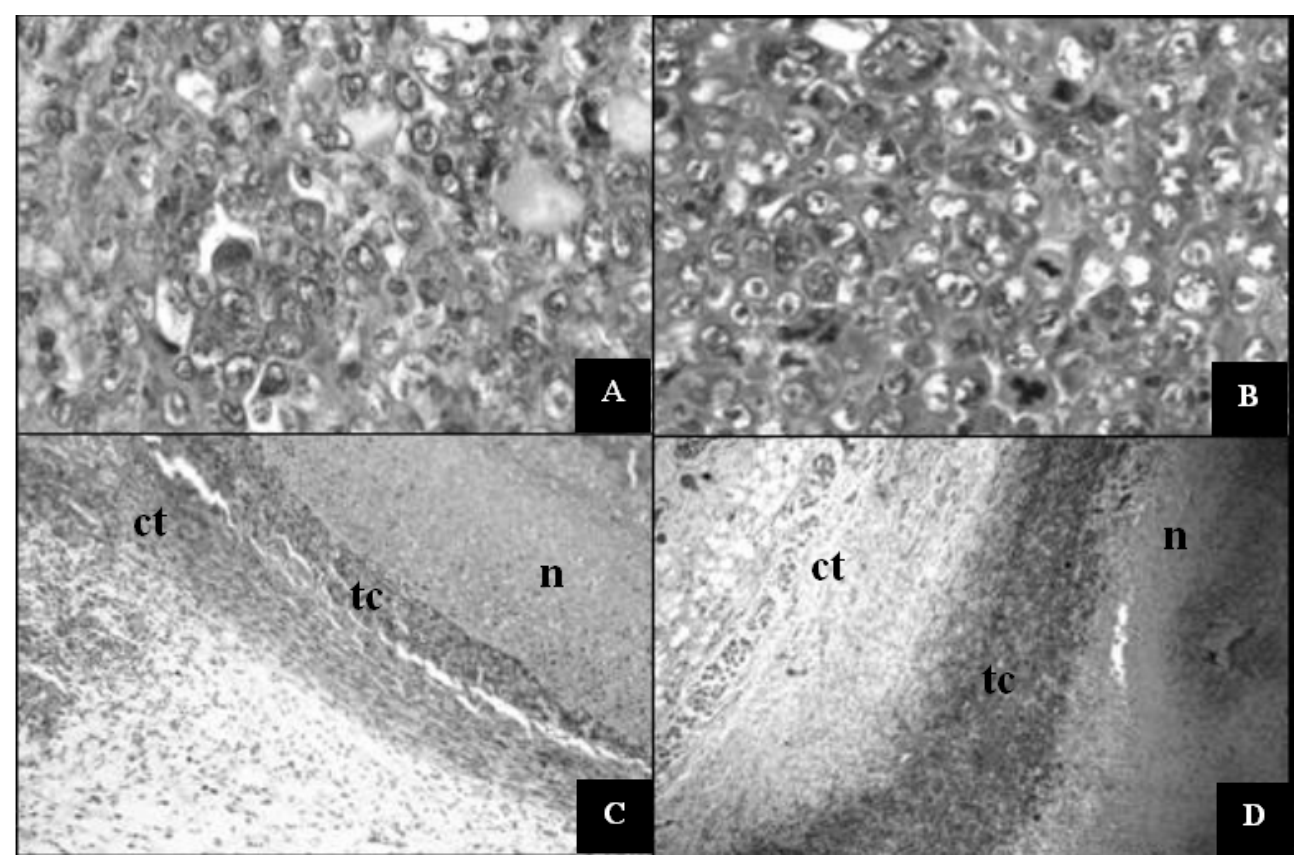




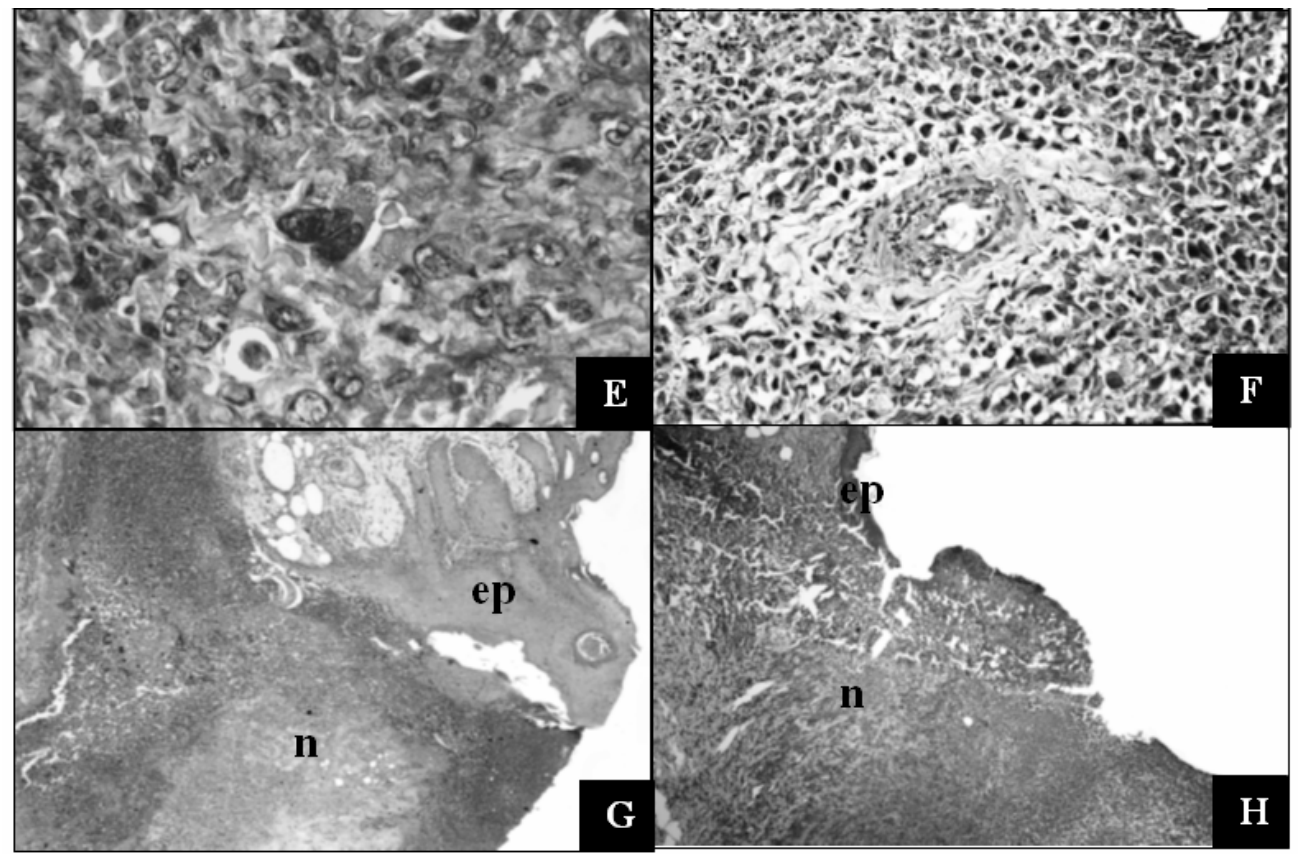

Figure 1 - At day 7, similar architectural morphology in the PEtn (A) and non-treated groups (B), revealing low degree of cell differentiation, large nuclei with a high number of vacuoles and prominent nucleoli (HE, objective 40X). At day 14, the neoplastic lesion in the PEtn group (C) showed better organization of the peripheral granulation tissue, suggesting a fibrous capsule, in contrast to non-treated group (D) (HE, objective $4 \mathrm{X}$ ). At day 14, the treated group (E) also showed an increased pattern of cohesion of the tumor cells, whereas the non-treated group (F) showed blood vessel destruction by less cohesive tumor cells (HE, objective 40X and 10X, respectively). At day 21, in the PEtn (G) and non-treated (H) groups, microscopic findings of the lesion were similar, with both groups showing extensive tumor invasion and necrosis (HE, objective $4 \mathrm{X}$ ). $\mathrm{n}=$ necrosis; $\mathrm{tc}=$ tumoral cells; $\mathrm{ct}=$ connective tissue; $\mathrm{ep}=$ epithelium.

(A)

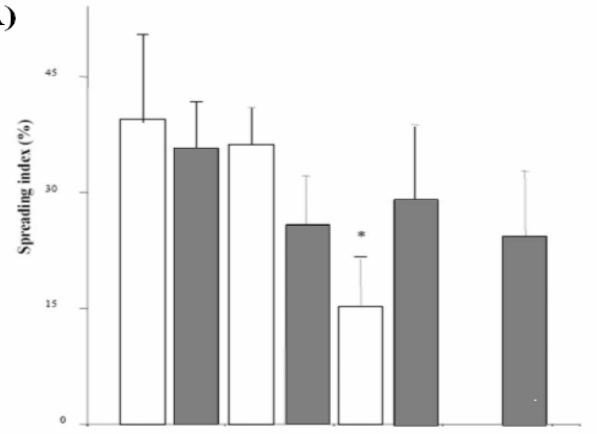

(B) 0.8

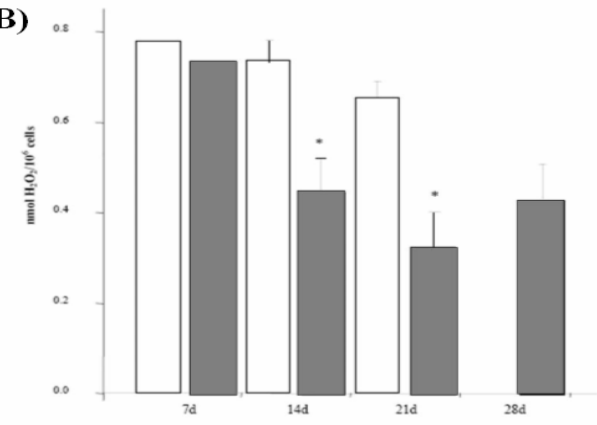

(C)

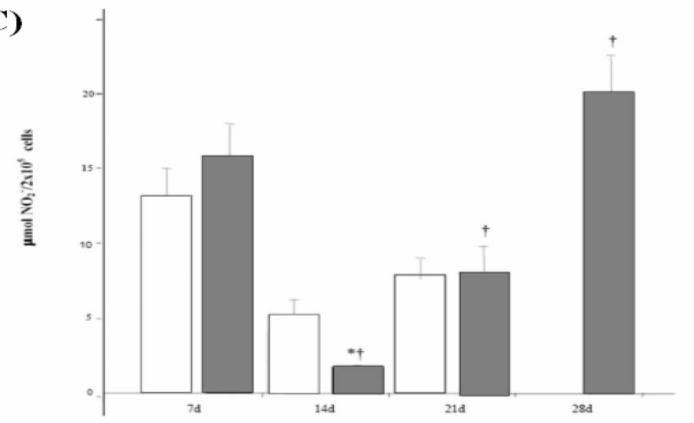

Figure 2 - Evaluation of the functional status of peritoneal macrophages from PEtn-treated (filled columns) and control (open columns) mice using the cell spreading technique. (A) Released $\mathrm{H}_{2} \mathrm{O}_{2}$, and (B) NO production (C). Data are reported as the mean \pm standard deviation. * $\mathrm{p}<$ 0.05 , compared to the control group. $\dagger \mathrm{p}<0.05$, compared to an earlier period. 


\section{DISCUSSION}

Phosphomonoesters are metabolites of phospholipids. They are produced by the action of phospholipases on phosphatidylcholine and phosphatidylethanolamine, and the levels of these compounds may be higher in situations of increased cellular growth and/or degradation. Thus, in the cases of tissue proliferation such as tumor growth, there are increased levels of phosphomonoesters relative to the levels in normal tissues during the stationary growth phase (Aiken and Gillies, 1996). Although these data are well known, the role of these lipids in tumor growth is still unclear.

In the present study, administration of the PEtn to Ehrlich tumors bearing mice resulted in increased survival time. Most of those in the non-treated group succumbed at 21 days, whereas those treated with the drug survived the 28-day experimental period. The mechanisms involved in this process are poorly understood. The data obtained from the animal and human experiments of diets with high levels of lipids suggest an involvement of polyunsaturated fatty acids in the development of immune responses (Yaqoob et al., 1994). It is known that the macrophages play a central role in both innate and acquired immunity. In the cancer environment, macrophages exhibit complex and multifaceted activities. They can be directly tumoricidal but may simultaneously support the tumor growth and dissemination. The expression of the macrophage tumouricidal capacity is dependent on their activation status.

Various agents, including the interferon- $\gamma$ (IFN- $\gamma$ ), lipopolysaccharide (LPS) and lectins are known to activate the macrophages (Suzuki et al., 2003; Schorey and Lawrence, 2008). Once activated, macrophages can inhibit the growth of tumor cells and microorganisms (Nascimento et al., 2002), mainly due to the increases in the production of $\mathrm{NO}, \mathrm{H}_{2} \mathrm{O}_{2}$ and cytokines.

To the best of our knowledge, there have been no studies on the effects of the PEtn on peritoneal macrophages in the animals bearing an Ehrlich solid tumor. Similarly, studies on the role of phospholipids in the macrophage respiratory burst are rare. According to Gordon et al. (1991), there is a direct correlation between the presence of PEtn and a decrease in the available superoxide anion $\left(\mathrm{O}_{2}^{-}\right)$. These authors observed that such events occurred due to phospholipid hydrolysis. Studying the neutrophils, the researchers showed that the decrease in the measured superoxide anions caused by the phosphorylethanoline was not due to an inhibition of cellular superoxide generation but rather due to the scavenging of the generated $\left(\mathrm{O}_{2}^{-}\right)$.

Because superoxide anion $\left(\mathrm{O}_{2}^{-}\right)$is converted to $\mathrm{H}_{2} \mathrm{O}_{2}$ in the cell, any element that affects the anion availability would consequently interfere with the production of the peroxide. Such phenomena may have occurred in the present study as macrophages from the mice treated with the PEtn released smaller amounts of hydrogen peroxide than those from the non-treated animals, especially after day 14. Because $\mathrm{H}_{2} \mathrm{O}_{2}$ production is involved in one of the mechanisms of macrophage cytotoxicity, these results may indicate an inhibitory action of the PEtn on the macrophage lysis activity. The data on the macrophage spreading also supported this premise, as animals treated with PEtn had decreased macrophage spreading compared to untreated animals. Finally, the lower levels of $\mathrm{H}_{2} \mathrm{O}_{2}$ may have contributed to the mechanisms that led to the increased survival time of the PEtntreated animals. That is, there is a direct correlation between $\mathrm{H}_{2} \mathrm{O}_{2}$ levels and angiogenesis (Monte et al., 2003), and solid tumor growth depends on local increases in blood vessel growth. NO is another important metabolite released by the macrophages. This free radical is produced by a group of enzymes called nitric oxide synthases (NOS). The inducible nitric oxide synthase (iNOS) is one of the three key enzymes that produce NO from the amino acid l-arginine. NO and iNOS are common in malignant tumors and are known to have both pro- and anti-tumor effects (Fukumura et al., 2006). Although the roles of NO and its metabolites in the carcinogenesis are not completely elucidated (Ellies et al., 2003), their effect have been described to be dose-dependent. The generation of high levels of NO by the activated macrophages may be cytostatic or cytotoxic for tumor cells, whereas modest NO production may have the opposite effect, promoting tumor growth $(\mathrm{Xu}, 2002)$. Tapieiro et al. (2002) showed that excessive levels of NO produced in inflamed tissues could lead to the nitration of tumor-suppressing proteins, contributing to carcinogenesis and tumor progression. The present data supported this premise, since the animals treated with the PEtn had decreased levels of NO at 14 days, when a delay in tumor growth was observed. After this period, the increasing levels of NO were noticed 
concomitantly with tumor progression. These results, in addition to reinforcing the importance of NO in the control of neoplastic development, indicated the important role of the PEtn in this process.

Taken together, these results confirmed the role of $\mathrm{NO}$ and $\mathrm{H}_{2} \mathrm{O}_{2}$ in the modulation of tumor growth and also showed the antineoplastic effects of oral administration of the PEtn on the survival time of Ehrlich tumor bearing-mice. Considering that the Ehrlich tumor is a mammary tumor of mice, the present data also indicate the promising role of the PEtn in the control of human neoplasia.

\section{ACKNOWLEDGEMENTS}

This study was financially supported by CNPq/Pibic and FUNDUNESP.

\section{REFERENCES}

Aiken NR, Gillies RJ.( 1996), Phosphomonoester metabolism as a fuction of cell proliferative status and exogenous precursors. Anticancer Res. 16 (3B):1393-7.

Bhaumik S, Khar A. (1998), Cytokine-induced production of no by macrophages induces apoptosis and immunological rejection of ak-5 histiocytic tumor. Apoptosis; 3, 361-8.

Bhaumik S, Mitra R, Varalakshmi C, Khar A. (2001), Activated macrophages migrate to the subcutaneous tumor site via the peritoneum: a novel route of cell trafficking Exp Cell Res. 266 (1), 44-52.

Campbell KA, Wu YP, Chacko VP, Sitzmann JV. (1990), In vivo 31P NMR spectroscopic changes during liver regeneration. J Surg Res. 49 (3), 244-7.

Ding AH, Nathan CF, Stuehr DJ. (1988), Release of reactive nitrogen intermediates and reactive oxygen intermediates from mouse peritoneal macrophages. Comparison of activating cytokines and evidence for independent production. J Immunol. 141 (7):2407-12.

Ellies LG, Fishman M, Hardison J, Kleeman J, Maglione JE, Manner CK, et al. (2003), Mammary tumor latency is increased in mice lacking the inducible nitric oxide synthase. Int J Cancer. 106 (1):1-7.

Erickson KL, Hubbard NE. (1996), Dietary fish oil modulation of macrophage tumoricidal activity. Nutrition. 12 (1 Suppl):S34-8.

Fukumura D, Kashiwagi S, Jain RK. (2006), The role of nitric oxide in tumour progression. Nat Rev Cancer. 6 (7), 521-34.
Gordon LI, Weiss D, Prachand S, Weitzman SA. (1991), Scavenging of superoxide anion by phosphorylethanolamine: studies in human neutrophils and in a cell free system. Free Radic Res Commun. 15 (1):65-71.

Kleeb SR, Xavier JG, Frussa-Filho R, Dagli ML. (1997), Effect of haloperidol on the solid Ehrlich tumor in mice. Life Sci., 60 (4-5):PL69-74.

Matsuzaki P, Akisue G, Salgado Oloris SC, Górniak SL, Zaidan Dagli ML.( 2003), Effect of Pfaffia paniculata (Brazilian ginseng) on the Ehrlich tumor in its ascitic form. Life Sci. 74 (5), 573-9.

Mitra R, Dharajiya N, Kumari L, Varalakshmi C, Khar (2004), A. Migration of antigen presenting cells from periphery to the peritoneum during an inflammatory response: role of chemokines and cytokines. FASEB J. 18 (14), 1764-6

Monte M., Davel L.E., Sacerdote D.E., Lusting E. (1997), Hydrogen peroxide is involved in lymphocyte activation mechanisms to induce angiogenesis. Eur $\mathbf{J}$ Cancer. 33 (4), 676-82.

Morvan D, Demidem A, Papon J, De Latour M, Madelmont JC. (2002), Melanoma tumors acquire a new phospholipid metabolism phenotype under cystemustine as revealed by high resolution magic angle spinning proton nuclear magnetic resonance spectroscopy of intact tumor samples. Cancer Res. 62 (6), 1890-7.

Nascimento FR, Silva BT, Viana JO, Cruz GB, Arruda K, Guerra RN. The anti-tumoral activity of vegetal species found in Amazonic region. Proceedings of the IV Congreso Latinoamericano de Inmunologia; 2002 Dez 9-13; Havana, Cuba.

Norman GR, Streiner DL. (1994), Biostatistics - The Base Essentials. St. Louis (MO): Mosby Year Book; $260 \mathrm{p}$.

Pinello KC, Fonseca Ede S, Akisue G, Silva AP, Salgado Oloris SC, Sakai M, et al. (2006) Effects of Pfaffia paniculata (Brazilian ginseng) extract on macrophage activity. Life Sci. 78 (12), 1287-92.

Rabinovitch M, Manejias RE, Russo M, (1971), Abbey EE. Increased spreading of macrophages from mice treated with interferon inducers. Cell Immunol. 29 (1), 86-95.

Russo M, Teixeira HC, Marcondes MC, Barbuto JA. (1989), Superoxide-independent hydrogen peroxide release by activated macrophages. Braz $J$ Med Biol Res. 22 (10), 1271-3.

Sakai M, Fonseca ES, Dagli ML, Palermo-Neto J. (2006), Diazepam effects on Ehrlich tumor growth and macrophage activity in mice. Life Sci. 78 (16), 1777-83.

Schorey JS, Lawrence C. The pattern recognition receptor Dectin-1(2008), from fungi to mycobacteria. Curr Drug Targets. 9 (2), 123-9. 
Sherrington EJ, Sanderson P, Calder PC. (1995), The effect of dietary lipid manipulation on macrophage cell surface molecule expression. Biochem Soc Trans. 23 (2), 272S.

Silva RJ, da Silva MG, Vilela LC, Fecchio D. (2002), Cytokine profile of Ehrlich ascites tumor treated with Bothrops jararaca venom. Mediators Inflamm. 11 (4), 197-201.

Suzuki M, Hisamatsu T, Podolsky DK. Gamma (2003), Interferon Augments the Intracellular Pathway for Lipopolysaccharide (LPS) Recognition in Human Intestinal Epithelial Cells through Coordinated UpRegulation of LPS Uptake and Expression of the Intracellular Toll-Like Receptor 4-MD-2 Complex. Infect Immun. 71 (6), 3503-11.

Tapiero H, Mathé G, Couvreur P, Tew KD. Arginine. (2002), Biomed Pharmacother. 56 (9), 439-45.
Wallace FA, Neely SJ, Miles EA, Calder PC. (2000), Dietary fats affect macrophage-mediated cytotoxicity towards tumour cells. Immunol. Immunol Cell Biol. 78 (1), 40-8.

Xu W, Liu LZ, Loizidou M, Ahmed M, Charles IG. (2002), The role of nitric oxide in cancer. Cell Res. 12 (5-6), 311-20

Yaqoob P, Newsholme EA, Calder PC (2002), The effect of dietary lipid manipulation on rat lymphocyte subsets and proliferation. Immunology. 1994; 82 (4), 603-10.

Received: March 04, 2010; Revised: October 07, 2010; Accepted: September 12, 2011. 
PÁGINA EM

BRANCO 